\title{
Convergence among imagination, social-emotional learning and media literacy: an integrative literature review
}

\section{Xanthippi Tsortanidou, Thanasis Daradoumis \& Elena Barberá-Gregori}

To cite this article: Xanthippi Tsortanidou, Thanasis Daradoumis \& Elena Barberá-Gregori (2020): Convergence among imagination, social-emotional learning and media literacy: an integrative literature review, Early Child Development and Care

To link to this article: https://doi.org/10.1080/03004430.2020.1753720

View supplementary material $₫$

\section{Published online: 18 May 2020.}

Submit your article to this journal $\square$

a)

View related articles

View Crossmark data \lceil 


\title{
Convergence among imagination, social-emotional learning and media literacy: an integrative literature review
}

\author{
Xanthippi Tsortanidou (10) ${ }^{a}$, Thanasis Daradoumis (10) ${ }^{b, c}$ and Elena Barberá-Gregori (1) ${ }^{\mathrm{a}, \mathrm{d}}$ \\ ${ }^{\mathrm{a} D o c t o r a l}$ School, Open University of Catalonia, Barcelona, Spain; ${ }^{\mathrm{b}}$ Department of Computer Science, Multimedia and \\ Telecommunications, Open University of Catalonia, Barcelona, Spain; 'Department of Cultural Technology and \\ Communication, University of Aegean, Mytilini, Greece; ${ }^{d}$ Department of Psychology and Education Sciences, Open \\ University of Catalonia, Barcelona, Spain
}

\begin{abstract}
An integrative literature review was conducted according to Coopers' guidelines in order to critique and integrate issues over the convergence among imaginative/Waldorf pedagogy, social-emotional learning and media literacy mindfulness in Primary and Secondary education. A comprehensive analysis of theoretical and empirical articles between 2005 and 2019 was provided. Three research questions were set, discussed and analysed highlighting the followinggaps in the literature: (i) the combination of imagination pedagogies with digital media and socialemotional development is neglected, (ii) there is a lack of longitudinal studies to analyse how social-emotional skills contribute to forming critical media literacy according to student's developmental stage, (iii) there is urgent need for reconceptualizing media literacy by encompassing and analysing its effects on cognitive, social-emotional and motivational skills development. We provide a framework presenting four perspectives, theoretical, developmental, pedagogical and social, supporting the relationship among imaginative pedagogy, media literacyand socialemotional skills.
\end{abstract}

\section{ARTICLE HISTORY}

Received 6 January 2020

Accepted 2 April 2020

\section{KEYWORDS}

Social-emotional education; media literacy; imagination

\section{Introduction}

More and more the aim of students' holistic development becomes a mandate, involving the equally development of each dimension of human being, namely cognitive, emotional, spiritual, and physical (Stehlik, 2008). This mandate seems to find its full implementation through Waldorf education which provides multifaceted education, by including the gradual unfolding of the three soul qualities of thinking (head), feeling (heart), and willing (hand). As its founder, Rudolf Steiner, states, imagination plays a crucial role in the development of these qualities; so the training of thinking, feeling and willing as well as the development of imagination, inspiration and intuition are crucial elements of the educational process (Stehlik, 2008). Each of these qualities is dominant in seven-year cycles (07, 7-14, 14-21), namely for the first cycle the willing, for the second the feeling, and for the third the thinking (Stehlik, 2008).

Waldorf pedagogy provides an environment that incorporates imagination-based teaching methods, such as storytelling, arts and the sense of wonder which can facilitate holistic development by balancing the intellectual, social and emotional dimensions. In fact, it focuses on all-rounder

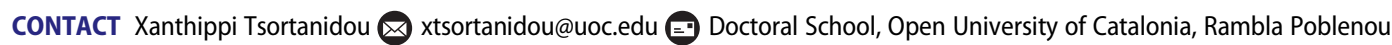
156, Barcelona 08018, Spain

(4) Supplemental data for this article can be accessed at https://doi.org/10.1080/03004430.2020.1753720. 
person development, respecting developmental appropriateness (Hether, 2001, as cited in Graber \& Mendoza, 2012).

In this context, students should be aware of expressing, managing and regulating their own emotions as well as comprehend others' feelings so that they are able to take moral decisions. The incorporation of Emotional Intelligence into school is a new wave of reform and aims mainly on the maximization of performance and utilizes modes of judgment, selection and regulation of emotions (Neophytou, 2013). Schools should intentionally aim at enhancing emotional and social skills through emotional competence (Banks, Sapp, \& Obiakor, 2013). Programmes aiming at teaching vital components of puberty education, namely empathy, relationship skills, conflict resolution and responsible decision-making show gain in students' behavioural competencies (Durlak et al., 2011, as cited in Collier-Harris \& Goldman, 2017). Moreover, Hatzigianni, Gregoriadis, and Fleer (2016) highlight that social-emotional development can be supported by imagination.

In addition, students have to develop their physical (willing), emotional (feeling) and intellectual (thinking) abilities as an indispensable basis for obtaining media competency (Hübner, 2015). The electronic media usage entails a lot of psychological activity imitation and thus, has a particularly seductive effect (Trimmel \& Bachmann, 2004). Digital connectivity raises 'social contagion' (Sawyer et al., 2012, as cited in Collier-Harris \& Goldman, 2017), since identical behaviours are encouraged and memes are transmitted as discrete cultural concepts, symbols and behaviours that 'infect' puberty (Collier-Harris \& Goldman, 2017).

Students' learning process has to be an active process where technologies should serve as means of knowledge building and skill development by taking into account the students' age, development as well as specific cognitive and emotional characteristics that can facilitate and complement this process (Joronen, Häkämies, \& Åstedt-Kurki, 2011; Silva, Cruz, \& Laureano-Cruces, 2006). This need is also escalated by the fact that digital media replace activities that are important for child development (Savina, Mills, Atwood, \& Cha, 2017). The integration of different media, social-emotional skills and the employment of visual, auditory and kynesthetic approaches (Mihailidis \& Cohen, 2013, as cited in Kosic, 2018) are challenges that should deal with the school curricula in the context of holistic development in a media-saturated century (Kosic, 2018).

The format of this literature review complies with the considerations of Cooper's (1982) methodology for integrative literature reviews. Cooper suggests a five-stage methodology included the identified research problem/research problem and research questions formulation, data collection/ literature search, data evaluation, data analysis and results presentation. According to Cooper, research reviews should follow the same criteria as primary studies in their methodological rigour because they can be deemed as research on research. More specifically, he conceptualizes the integrative review as a reseach project that abides by scientific principles based on four characteristics the asked research question(s), the primary function in review, procedural differences that evoke variations in conclusions and sources of potential invalidity in conclusions - that are covered within the aforementioned five stages (Cooper, 1982).

\section{Research problem and research questions formulation}

The relationship among imaginative and holistic pedagogy, social-emotional education and media literacy is vague. Research attempts so far are intended to explore these issues separately and although there are cues about their interrelationships, there is no framework that incorporates them in an integrated manner. This article contributes towards this direction by revealing the gaps in the current literature. The main working hypothesis is whether there is an educational framework that employs the imaginative teaching methods for media literacy and emotional intelligence skills development through the lens of Waldorf pedagogy. Based on the above problem, the topic of this integrative review was framed by the following research questions and is summarized in the IMSE triangle, shown in Figure 1. 


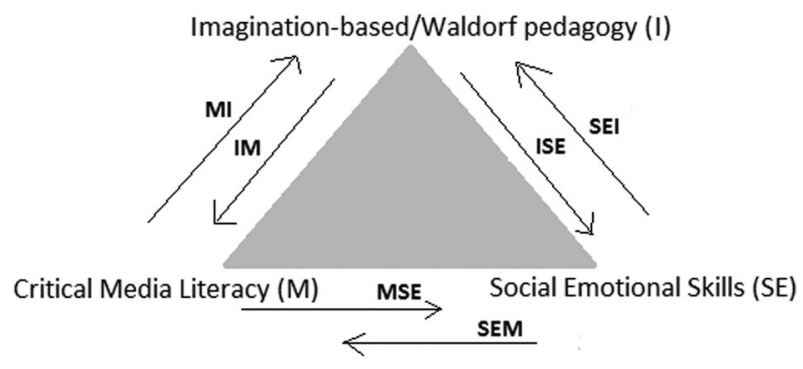

Figure 1. The IMSE triangle.

RQ1: How imagination teaching methods (like storytelling, arts, drama/role play, empathy, discussion, exploration and routine) affect the development of emotion awareness (self-awareness, empathy and social awareness)? (ISE)

RQ2: How social-emotional skills (self-awareness, social awareness, self-management, relationship skills and responsible decision-making) contribute to the development of appropriate media competency/new media literacy culture based on student's developmental stage? (SEM)

RQ3: How media literacy can engage and support the three learning faculties and the fundamental classes of mental operations, namely the physical involvement (willing/motivation), the human connection/emotional development (feeling/emotion) and the intellectual development/reason (thinking/cognition), which form the base of Waldorf pedagogy? (MI)

\section{Data collection}

\section{Literature search strategy}

In order to answer the research questions, keywords that reflect the key concepts of each question were used. General and more specific keywords and the operation of OR, AND to specify and, at the same time, broaden the search scope were used as well. For example, some keywords for RQ1 are (imaginati*) AND (teaching methods OR learning) AND (emotion* awareness) AND (empathy) AND (self-awareness); for RQ2 are (social-emotional skills OR social-emotio* competen* OR socialemotional literacy OR social-emotional intelligence OR social-emotional education OR learning OR development) AND (media competen* OR media literacy OR new media literacy OR media pedagogy); for RQ3 are (media competen* OR media literacy OR new media literacy OR media pedagogy) AND (mental operations). The complete list of keywords is presented in Appendix A.

\section{Pilot review}

In order to refine the initial planning of protocol, namely the inclusion and exclusion criteria (see Table 1), a pilot review was conducted on ERIC and ScienceDirect, since they include a wide range of research areas relevant to our topic. Two iterations were conducted on both databases in order to assess the number of identified articles (first iteration) and add alternative keywords (second iteration). In the second iteration, we obtained more results since new keywords were added ('imagination-based teaching methods', 'digital literacy', 'technology literacy', 'transmedia literacy', 'transformative education or learning').

\section{Inclusion and exclusion criteria of the literature search}

Because of the difficulty to find articles that cover the whole spectrum of each research question, it was considered meaningful to include both theoretical and empirical articles as well as articles that cover only one variable. 
Table 1. Inclusion and exclusion criteria of the literature search.

\begin{tabular}{|c|c|}
\hline Inclusion criteria & Exclusion criteria \\
\hline $\begin{array}{l}\text { Publications should be original research work and provide empirical } \\
\text { evidence through Randomized Controlled Trial (RCT), and } \\
\text { quantitative and qualitative research }\end{array}$ & $\begin{array}{l}\text { Publications that are presented as posters in } \\
\text { conferences }\end{array}$ \\
\hline Publications should provide theoretical background & Publications that their upper number of pages is four \\
\hline Publications should include at least five pages & Publications that include only abstracts \\
\hline Publications after 2005 are considered & $\begin{array}{l}\text { Updated versions of publications from the same author } \\
\text { are considered only once, the last update one }\end{array}$ \\
\hline $\begin{array}{l}\text { Publications include: Journals, Conference proceedings, Dissertations, } \\
\text { Book chapters, (Systematic) Literature reviews, Primary studies, } \\
\text { Qualitative studies }\end{array}$ & $\begin{array}{l}\text { Book chapter reviews that have not their full text } \\
\text { available }\end{array}$ \\
\hline $\begin{array}{l}\text { Publications that fall into PICO (Population: Primary and Secondary } \\
\text { school students; Intervention: School-based/Community-based } \\
\text { interventions; Context: Transformative education advocating social- } \\
\text { emotional development, emotional intelligence, imagination-based } \\
\text { teaching methods and media competency; Outcomes: } \\
\text { appropriateness of intervention to age groups-effectiveness in } \\
\text { developing social-emotional skills and obtaining media competency) }\end{array}$ & Publications that are not written in English \\
\hline Publications should have their focus on the above-stated keywords & Publications that have not their full text available \\
\hline $\begin{array}{l}\text { Publications should fall into the following fields: Educational } \\
\text { Technology, Educational Neuroscience, Developmental Cognitive } \\
\text { Neuroscience, Psychology of Media Education, Developmental } \\
\text { Psychology, Educational Psychology, Philosophy of Education, } \\
\text { Positive Psychology, Positive Education, Alternative Education, } \\
\text { Holistic Education }\end{array}$ & $\begin{array}{l}\text { Publications that their focus is other than the above- } \\
\text { stated }\end{array}$ \\
\hline
\end{tabular}

We used the PICO strategy (Santos, Pimenta, \& Nobre, 2007) and we defined selection criteria for retaining or discarding the literature (Meline, 2006). Particularly, the PICO strategy specifies studies that fall into the scope and purpose of this review, namely population (students), intervention (school-based/community-based), context (social-emotional development, emotional intelligence, imagination-based teaching methods and media competency) and outcomes (appropriateness of intervention to age groups-effectiveness in developing social-emotional skills and obtaining media competency) (Santos et al., 2007).

More specifically, the inclusion criteria are consistent with the research purpose and research questions of this review including the field of research, the population of interest (students), the age of the literature (work published after 2005), the education level of the topic (primary and secondary education), the scholarly literature (empirical studies employed randomized Controlled Trial $(\mathrm{RCT})$, quantitative and/or qualitative research and theoretical studies as well) and the page limitation of literature (above five pages). The exclusion criteria are related to page limitation, studies availability and language (Meline, 2006). The PICO strategy and the selection criteria are summarized in Table 1.

\section{Existing literature}

The literature search was conducted in eleven digital databases. The databases that were deployed are: ERIC, ProQuest, Scopus, Web of Science, ScienceDirect, Oxford University Press, SAGE, SpringerLink, Taylor \& Francis, Cambridge Journals Online, Wiley InterScience. The other sources were found through the references of some selected articles. As shown in Table 2, during the literature search

Table 2. Summary of the identified body of literature.

\begin{tabular}{lccc}
\hline RQs & $\begin{array}{c}\text { Identified } \\
\text { research works }\end{array}$ & $\begin{array}{c}\text { Research works that } \\
\text { meet the criteria (phase 1) }\end{array}$ & $\begin{array}{c}\text { Research works that are } \\
\text { included in the analysis (phase 2) }\end{array}$ \\
\hline RQ1 & 1244 & 109 & 34 \\
RQ2 & 953 & 78 & 13 \\
RQ3 & 1043 & 83 & 15 \\
Total & 3240 & 270 & 62 \\
\hline
\end{tabular}


process, 3240 articles were identified, from which 270 were considered relevant to at least one variable of each RQ at first place (phase 1). These articles were assessed by title, keywords and abstract and fall into the PICO. A deeper screening was conducted in order to meet the inclusion and exclusion criteria exactly (see Appendix B for complete list of excluded data points). Table 2 summarizes the two phases we followed.

The majority of articles for the first research question (RQ1) is mostly concerned with preschool education and teaching of Mathematics, whereas a significant amount of literature is dedicated to empathy as a standalone research topic. Also, imagination-based teaching methods are used especially for the teaching and improvement of reading and writing skills in primary education. Research works that examine the relationship between self-awareness and imagination-based teaching methods are hardly found. In addition, most research papers primarily employ storytelling and (multi-)arts as appropriate imagination-based teaching methods for the targeted age group (Primary and Secondary school students) and secondarily the discussion method as supplementary to the storytelling method. In contrast, routine teaching method is addressed to the preschoolers. As for empathy, most studies focus on teacher training in cultivating their ability to empathize with their students and reflect upon their practice, while a limited number of studies has concentrated on how to cultivate students' empathy utilizing arts.

The search results for the second research question (RQ2) mainly concern children's academic, cognitive and intellectual growth, cooperative learning and social interaction, peer/teacher interaction, gender equity issues and children with emotional and behavioural difficulties. The scenery about this RQ is vague and it is difficult to find related research works. Research attempts mostly concern the negative aspect of media and potential harmful impacts on child, a point that also is highlighted in relative literature (Wilson, 2008). The term 'transmedia literacy' is a novel term that appeared almost in the last decade and there are some articles that refer to it as a separate form of literacy. Regarding social-emotional education, literature refers mainly to preschool education, special education, teacher education and prevention programmes (drugs, bullying, etc.). More specifically, the focus is on academic learning, while the social-emotional context in which it takes place is examined through the lens of academic achievement for higher education, less for high school and hardly for primary school students.

Lastly, as concerns the third research question (RQ3), the existing literature about 'media/digital/ technology literacy and mental operations/psychological processes (motivation, emotion, cognition)' is underexplored. However, a significant amount of work has been identified with respect to 'media/digital/technology literacy and imaginative teaching methods' especially along with storytelling and arts.

\section{Data evaluation}

Taking into consideration Cooper's sources of variance, we specify the following limitations in our review: the criteria that are employed for the evaluation of data quality may differ among reviewers; exclusion criteria impose further limitations (date, language, not available full research works, works that have not exceed the limit of four pages) which result in incompleteness of reporting primary studies, a fact that is beyond the reviewer's control. As for the data evaluation, we consider research works that were published in peer-reviewed journals or are doctoral dissertations. As for the strength of evidence, mostly quasi-experimental and observational research designs are used and rarely experimental research design (You, Lee, Lee, \& Kim, 2018). The sample size is limited to an average of 80 participants, except from Clark (2007), Hatzigianni et al. (2016), Bourgeois, Bower, and Carroll (2014) and Akti and Gürol (2012), a fact that does not allow generalization of the findings. Therefore, we can deduce that the evidence is of moderate quality. In general, what is missing are longitudinal studies and quantitative research methods investigating the causal relationships, not offering only descriptive information. 


\section{Data analysis}

Driven by Cooperś guidelines and our RQs, our study will synthesize the extensive body of literature and provide a new representation of the topic based on each research question and the missing points.

RQ1: How imagination teaching methods (like storytelling, arts, drama/role play, empathy, discussion, exploration and routine) affect the development of emotion awareness (self-awareness, empathy and social awareness)?

Self-awareness seems to be a neglected term if we consider its development in combination with imagination-based methods; its analysis is basically found in theoretical articles as a skill that is developed in the context of art-based programmes and in correspondence with other social skills, such as cooperation (Arslan, 2014). What is underexplored in the literature is the development of self-awareness through imaginative methods other than arts and what seems surprising is the fact that selfawareness is overlooked, while it is the prerequisite for empathy and social-awareness development. Self-awareness is a narrative of self, a personal story that is activated through social relationships. It is inextricable with social awareness and is a valuable socio-emotional instrument for creating 'identity capital' (Warin \& Muldoon, 2009).

In addition, much has been written about empathy but little has been empirically done in order to broaden its scope in educational research. Although at theoretical level, empathy is separated in two senses, the cognitive and the affective one (Cuff, Brown, Taylor, \& Howat, 2016; Keskin, 2014; Wirling, 2014), this does not occur when it is empirically approached. You et al. (2018) clearly claim that their intervention aims at developing cognitive empathy through arts-project but fail at developing affective empathy. According to Decety and Jackson (2006), empathy entails three components: an affective response, which may include sharing of emotional state; a cognitive capacity to take the other's perspective; and emotion regulation. The third component is missing in literature when the target is empathy. Goldstein and Bloom (2010) make a clear distinction among theory of mind, empathy and emotion regulation in order to teach them through multi-arts approach. Another troubling issue is self/social-awareness, as an emotional intelligence skills, which breed empathy that connects the emotional intelligence with morality. The crucial point is whether emotional intelligence encompasses morality or not. In case of not, a Machiavellian personality can be considered as emotional intelligent; in case of yes, the development of a moral personality is random (Kristjánsson, 2006). This issue is highlighted empirically by You et al. (2018) who stress the connection among empathy, moral reasoning and prosocial behaviour, a finding that indicates the need for an empathy-based learning curriculum. Imagination is one of the stages of empathetic process, a fact that indicates its inextricable bond with empathy (Keskin, 2014). The development of empathy is facilitated by Nussbaum's 'narrative imagination' which is the ability to think being in another's situation and is essential component of moral dimension and can cultivate the socialawareness skill (Kim \& Wiehe-Beck, 2016). It can also collaborate actively with sociological imagination so that an empathizer explores how others view an issue and be transported in space and time, experiencing a transcendent moment or epiphany (McCoy, 2012). The sociological imagination, to our knowledge, does not exist as a purpose in the current literature.

RQ2: How social-emotional skills (self-awareness, social awareness, self-management, relationship skills and responsible decision-making) contribute to the development of appropriate media competency/new media literacy culture based on student's developmental stage?

Media literacy when combined with socio-emotional literacy improves the social and interpersonal relationships among students but further research is needed in this direction to get a more comprehensive picture (Kosic, 2018). Although self-awareness enables one to obtain the perspectivetaking of others (social-awareness) and exercising self-control through self-regulation (Morin, 2011, as cited in Nielsen, 2017), Kosic (2018) aims at self-awareness development in the context of media competency and life skills. Despite the fact that electronic/screen media play a crucial role 
in children's emotional development there is a scarcity of studies that address these issues and, to our knowledge, the long-term, controversial consequences of children exposure to electronic media on emotional development and empathy have not been investigated until now (Hatzigianni et al., 2016; laosanurak, Chanchalor, \& Murphy, 2016; Pfaff-Rüdiger, Riesmeyer, \& Kümpel, 2017; Savina et al., 2017; Wilson, 2008). An exception constitutes the television medium, as the research is focused on its detrimental effects. Jenkins et al. (2006, as cited in Graber \& Mendoza, 2012) suggest that media literacy skills are all essentially social skills and include play, performance, simulation, appropriation, multitasking, distributed cognition, collective intelligence, judgment, transmedia navigation, networking, and negotiation. By extension, they argue that Waldorf education emphasis' on art cultivates visualization, judgment and appropriation skills and the dramatic storytelling develops performance, simulation and play skills (Graber \& Mendoza, 2012). According to Durlak, Weissberg, Dymnicki, Taylor, and Schellinger (2011, as cited in D'Amico, 2018), technologies are rarely used as tools in the socialemotional development and it is difficult to find published empirical research that focuses on the effectiveness of technologies for enhancing social and emotional health of children. For a long time, media literacy has concentrated on cognitive or evaluative skills (Koltay, 2011, as cited in Pfaff-Rüdiger et al., 2017) but current social online practices indicate that emotional, motivational and social skills are involved as well and new media literacy skills should combine both social practices and constitutive skills (Sutter, 2010, as cited in Pfaff-Rüdiger et al., 2017). Hatzigianni et al. (2016) highlight the impressive scarcity of research attempts on whether or not technologies can benefit social-emotional development. So far, concepts like self-concept, self-competence, self-efficacy and self-esteem were studied as they have significant impact on students' emotional and behavioural well-being. A key gap in literature is the investigation of the interrelationship among technology, social-emotional outcomes and imagination in children.

RQ3: How media literacy can engage and support the three learning faculties and the fundamental classes of mental operations, namely the physical involvement (willing/motivation), the human connection/emotional development (social/emotion) and intellectual development/reason (thinking/cognition), which form the base of Waldorf pedagogy?

The current trend is towards multi-screen media usage and a shift has occurred from television to computer and mobile phones, overtaking all other devices to become the 'screen of screens' (Bond, 2013; Bringué \& Sádaba, 2011, as cited in Aierbe-Barandiaran \& González, 2016). Papoutsi and Drigas (2017) state that the investigation about mobile technologies and empathy is now starting for children. Emotions are valued more highly in media than in daily life (Bartsch, Vorderer, Mangold, \& Viehoff, 2008, as cited in Aierbe-Barandiaran \& González, 2016) and play a key role in determining children's media usage (Jones, 2010; Soto \& Vorderer, 2011, as cited in Aierbe-Barandiaran \& Oregui-González, 2016). Therefore, more research should be done toward this direction. As for media literacy and cognition, this interrelationship is not sufficiently investigated so far. Most research work has been done about television, which still remains the dominant medium during childhood, while research for interactive screen media is lacking. As for television medium, the background television, i.e. the indirect exposure, may have a negative impact on executive function, attention skills, spatial cognition, mental elaboration, imagination, creativity, story comprehension and language development but these findings are supported by few studies and concern mainly preschoolers. In general, empirical evidence is not strong and we cannot argue that media use is totally harmful or beneficial to children's cognitive development (Anderson \& Kirkorian, 2015; Anderson \& Subrahmanyam, 2017). There are some critical periods in child's development that media exert the strongest impact and the developmental appropriateness of media content is crucial as well. However, there is little evidence about these issues (Anderson \& Kirkorian, 2015). Bauman and Tatum (2008, as cited in Graber \& Mendoza, 2012) suggest that young children are not developmentally ready to understand the dynamics of media and cannot distinguish between reality and the virtual world. Waldorf pedagogy resists on introducing any type of technology until the age of 12 , a statement that is in accordance with developmental reports of Piaget and Kohlberg (Oppenheimer, 
2003, as cited in Graber \& Mendoza, 2012), who believed that in this age, the child is still developing the cognitive capacities. Anderson and Kirkorian (2015) and Anderson and Subrahmanyam (2017) argue that the media effects on brain development/cognition is so far unexplored and the cognitive processes that accompany the media use as well, except for research on cognitive processes underlying reading development (Clark, 2012; Cummings \& Vandewater, 2007; Jackson et al., 2006; Weis \& Cerankosky, 2010, as cited in Anderson \& Kirkorian, 2015). Another pending issue in literature is the exploration of interconnection between motivational skills and media usage. Pfaff-Rüdiger et al. (2017) employ the self-determination theory and developmental tasks to examine the process of gaining media literacy towards combining media literacy and motivation. In their study, participants aged 9-19 note high motivational skills but lack in emotional and evaluative skills, while the largest deficits were reported in social competence. Since this relationship is underexplored, more research works should be done to support these findings.

\section{Presentation}

In this section we present four perspectives, namely theoretical, developmental, pedagogical and social, that are distilled from the analysis and support the relationship among imaginative pedagogy, media and social-emotional skills. Following Cooper, in this stage we formulate and present a model that integrates all the concepts and relationships among the topics identified above and describes the four perspectives in more detail below. We call this model SEMI, being a model of Social Emotional and Media skills development through Imaginative pedagogies, and we depict it in Figure 2.

\section{Theoretical perspective}

Environments that incorporate imagination-based methods recognize the importance of socially situated context by employing: experiential-constructivist learning theory (Dewey, 1916; Piaget, 1971, as

\section{SEMI MODEL}

\section{Social Emotional and Media skills development through Imagination}

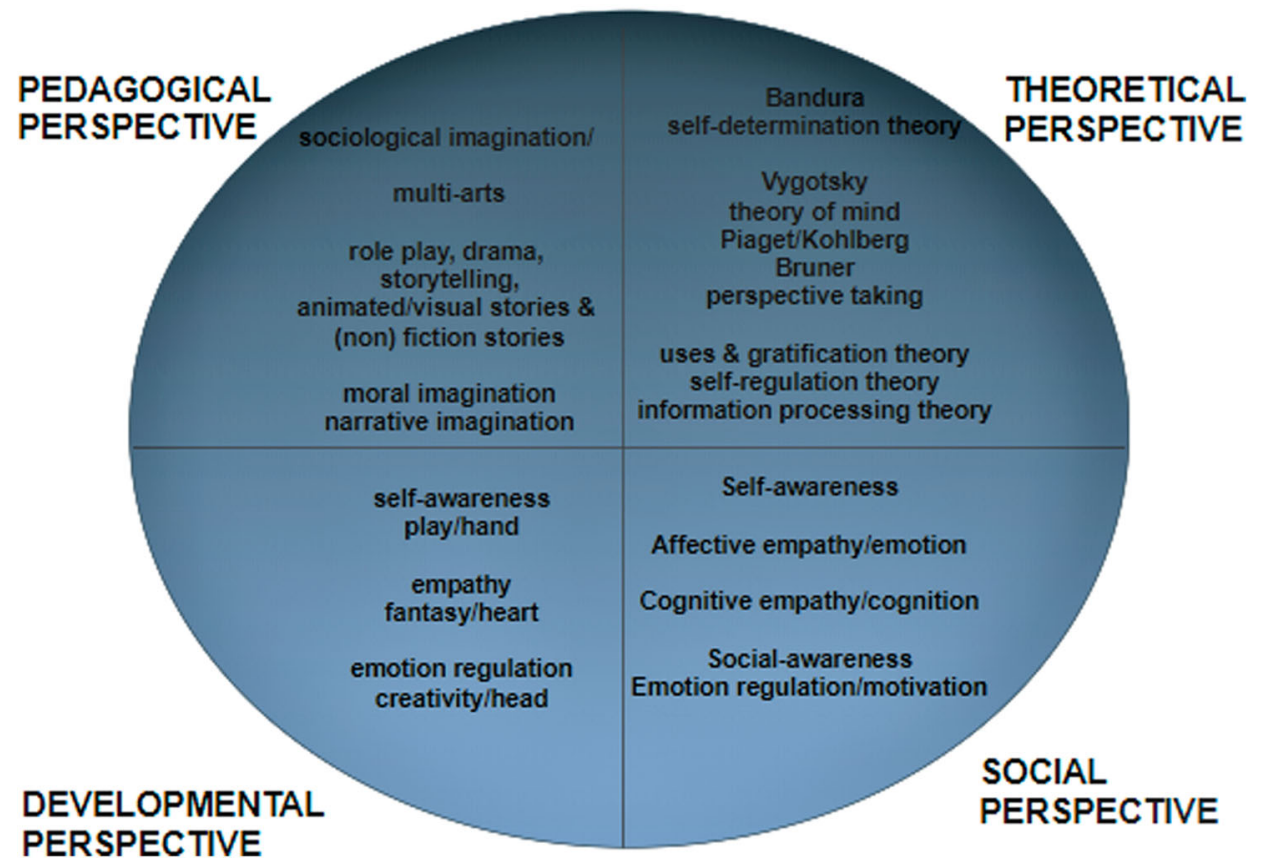

Figure 2. The SEMI model. 
cited in Nielsen, 2006; Shank, 2016); project-based learning (Ruokonen \& Ruismäki, 2015); situated learning (Bruner, 1996, as cited in Blatt-Gross, 2010); situated cognition by using cognitive apprenticeship model (Brown, Collins, \& Duguid, 1989, as cited in Blatt-Gross, 2010); Vygotsky's zone of proximal development (Vygotsky, 1978, as cited in Blatt-Gross, 2010). Studies that aim at a multi-arts programme (Clark, 2007; Goldstein \& Bloom, 2010; Joronen et al., 2011; Kim \& Wiehe-Beck, 2016; Ruokonen \& Ruismäki, 2015; Shank, 2016) take into consideration Vygotsky's theory of art (1971, as cited in Hedegaard, 2016), with arts satisfying human's cognitive, emotional and social needs. From this point of view, arts education constitutes the social and emotional form of cognition (Blatt-Gross, 2010). Bandura's social cognitive theory or social learning states that children learn ideas, values, emotions, and even behaviours by observing others in their social environment and in the media as well. Children are more likely to imitate observed behaviours when they perceive characters as similar to themselves as well as behaviours that are rewarded than those that are punished (Calvert, 2015). Also, based on information processing theory, Huesmann (1986, as cited in Wilson, 2008) points out the power of media and theorizes that children develop scripts for several routines, either in real life or through the media. These scripts can be retrieved from memory at any time, especially when the situation at hand resembles the features of the script. The uses and gratification theory explains why we use media. Children select specific media content and experiences to satisfy specific emotional and social needs. There are three main motivations to use media: diversion and escape, personal identity construction or social utility, and gaining information (Rubin, 2002, as cited in Calvert, 2015).

\section{Developmental perspective}

The most responsive and sensitive age group to imaginative stimuli is between 7 and 14 years old, namely the second seven year-cycle, called the feeling cycle (Steiner, 1974, as cited in Nielsen, 2006). Imaginative teaching is vital for the holistic and multifaceted development of child (Nielsen, 2006) and in every developmental stage child should be provided with both affect and cognition stories (Egan, 2005, as cited in Shank, 2016). However, though imagination-based teaching methods are more frequent until the age of 12 , this claim is not reflected by empirical evidence. In fact, studies focus mostly on elementary and middle school years' students for empathy development. Generally, the lack of life experiences may affect empathy, since when a child empathizes with another he/she cannot fully understand and interpret the social circumstances which require sensitivity (Fletcher, 2016). Empirical evidence shows that art-based methods facilitate the intellectual and emotional development and evoke emotional responses (Mynaříková, 2012). The age per se for social and emotional development is the early and mid-puberty, around 10-11 years old, because humans in this age are more self-conscious, whereas the ages 10-14 years old is the ideal age for empathy development (Burnett, Thompson, Bird, \& Blakemore, 2011). Despite these findings, emotion awareness is not examined empirically in relation to imagination so far. In partial contradiction to Burnett et al. (2011), empathy at middle childhood (ages from 6 to 12 years old) remains stable throughout lifespan (Rosenblum \& Lewis, 2003, as cited in Goldstein \& Bloom, 2010) in contrast to self-regulation which continues developing. Research results on empathy in adolescence are not clear, but females at this period have higher levels of empathy than males (Jolliffe \& Farrington, 2006, as cited in Goldstein \& Bloom, 2010). This confusion among ages regarding which period is the most fruitful for the development of empathy may be explained by the two senses of empathy, the cognitive and affective one. Affective empathy addresses the early ages, whereas cognitive empathy the later ones. This distinction is not clearly defined in the literature, so we suppose that cognitive empathy development coincides with emotion regulation development, as the transition from childhood to adolescence indicates cognitive development, a fact that facilitates both processes. Higgins (2016) states that in early adolescence, a dramatic shift occurs in socially regulated self-regulation, as children understand and share a variety of viewpoints, improve their social perspective-taking skills, which are associated with prosocial behaviour. The time gap between ages 11 and 13 is considered critical for the 
development of emotion regulation skills. Between ages 14 and 16, a refinement of various cognitive strategies occur, such as perspective taking and empathetic concern. Finally, between ages 17 and 19 , the frequency and successful use of emotional regulation strategies, such as perspective taking, empathetic concern, and reassessment of the situation are similar to that of adults (Garnefski \& Kraaij, 2006; Guyer et al., 2014; Silvers et al., 2012; Van der Graaff et al., 2014, as cited in Sabatier, Restrepo Cervantes, Moreno Torres, Hoyos De los Rios, \& Palacio Sañudo, 2017).

\section{Pedagogical perspective}

Nielsen (2006) discerns drama or role play, exploration, story, ritual and routine, arts, discussion and empathy as imagination-based teaching methods. Besides, Egan and Judson (2009) specify that cognitive tools of story, mental images, abstract binary oppositions, jokes and humour, sense of mystery, sense of reality, extremes of reality and limits of experience, association with the heroic, transcendent human qualities and sense of wonder, promote imagination. Although the levels of empathy that are activated by drama are also activated by engagement with fiction narratives (Goldstein \& Bloom, 2010), we have not encountered studies using fictional stories as vehicle for empathy development. Contrary to theoretical evidence, in their study Aierbe-Barandiaran and Oregui-González (2016)found that the level of empathy was higher in non-narrative form. Stehlik (2008) states that the power of storytelling is paramount, as it transmits moral messages and archetypal images in a way that 'speaks to child' consciousness' and can be used for cultivation of narrative imagination (Kim \& Wiehe-Beck, 2016). Role play or drama method belongs to embodied pedagogies and is notified as the ideal method for developing emotional empathy (Rudebeck, 2002, as cited in loannidou \& Konstantikaki, 2008), social-emotional skills (Arslan, 2014; Joronen et al., 2011), moral values (Goldstein \& Bloom, 2010), self-awareness and conflict management (Joronen et al., 2011). Multi-arts approach is used to improve communication, cooperation, emotion management skills and identity enforcement (Mynaříková, 2012). Clark (2007) summarizes which arts cultivate specific skills. In particular, visual arts are used for developing perceiving emotion; dance for perceiving and understanding emotion; music or drama for perceiving, understanding, utilizing and managing emotion; and multi-arts for managing and utilizing emotion. Friesem (2016) combines empathy phenomena with digital and media literacy competencies and summarizes that story-planning cultivates cognitive empathy; video pre-production develops projective empathy (role taking); video production develops affective empathy; video post-production cultivates psychological empathy (perspective taking); and screening (distribution) develops aesthetic empathy. Jones (2010) as well as Ying and Blanchfield (2010) propose visual stories (animated stories) to exercise communication skills. They implement them deliberately through non-verbal aspects, such as gestures, facial expressions, body language, postures and movements to communicate different dispositions and gradients of emotions. Robin (2006) suggests that educational benefits in emotional intelligence and social learning may come from digital storytelling that supports different learning styles, as well as technology and media literacy. Fleming (2013), Mills and Unsworth (2018), Pietschmann, Völkel, and Ohler (2014), Rodriguez-lllera and Castells (2014) also highlight the power of transmedia storytelling as the ideal aesthetic form in an era of collective intelligence.

\section{Social perspective}

The management of emotions requires self-, other-awareness and expression of them, a fact that indicates emotional sophistication and predicts social functioning (Wilce \& Fenigsen, 2016). Social functioning, based on both personal, first-hand and social, second-hand experiences, implies that humans broaden their repertoire of experiences through imaginative thought and gain them through multiple ways, such as from interactions with books, artworks, narratives, etc. (Eckhoff \& Urbach, 2008). Social processing can be achieved through stories (Whalen, 2010) that can satisfy human psychosocial needs and offer social-emotional benefits, such as deriving meaning, practicing abilities to 
understand the self and the others, dealing with real-life social interactions and relating with others successfully. This satisfies the need to belong by providing para-social relationships, re-examining past experiences, evoking empathy and autobiographical memories (Dill-Shackleford, Vinney, \& Hopper-Losenicky, 2016). One can also familiarize him/herself with several characters, situations and appropriate actions that lead to shape possibilities and expectations (Gallagher, 2012). Although the power of story is well-documented theoretically, the above benefits are neither fully explored empirically nor examined through various media. Arts can serve similar social-emotional benefits, such as recognizing, expressing and managing emotions, enhancing self- and other-awareness and responsible decision making (Arslan, 2014; Joronen et al., 2011). Therefore, we cannot ignore the cognitive, emotional and social benefits that arts have to offer in education (Blatt-Gross, 2010). It will be worthy to investigate whether media pose obstacles or facilitate the aforementioned benefits and examine the claim of Franks (2014) that the development of social skills may be impaired by social media, by creating superficial relationships and cultivating casual empathy and other crucial social skills.

\section{Conclusions}

Although years ago Maxwell and Reichenbach (2005) argued that educating emotions is a taboo subject, this claim still remains a troubling issue in literature. Wilce and Fenigsen (2016) also highlight this argument by proposing emotion pedagogies as a more adequate paradigm for developing flexible citizens through the shift from academic skills to self/social awareness and integrating imaginative thinking into child's experiences. Toward this direction, imaginative methods that Waldorf pedagogy proposes can achieve this goal. In literature, imaginative pedagogies, such as storytelling and multiarts approaches, are commonly used for emotion awareness development, whereas the remaining pedagogies, such as empathy, discussion, exploration and routine are absent from this aim.

The analysis of the selected theoretical and empirical studies between 2005 and 2019 indicates missing points in exisiting literature. The partnerships among imaginative pedagogies, digital media and social-emotional development constitute a neglected issue and should be investigated rigorously in future studies. This missing point is stressed by Hatzigianni et al. (2016) and Rosiek and Beghetto (2009) in that the integration of emotional and imaginative dimensions should be incorporated into educational process fostering the development of critical media literacy skills. Consequently, it would be meaningful to involve both social practices and cognitive, motivational, emotional and social skills into media literacy reconceptualization. Another missing point is the lack of longitudinal studies in analysing how social-emotional skills contribute to develop critical media literacy through age-appropriate teaching methods. These missing points could be investigated by future studies more rigorously exploring potential partnerships among educationallyappropriate and age-responsive methods, such as imaginative and emotion pedagogies.

\section{Disclosure statement}

No potential conflict of interest was reported by the author(s).

\section{Funding}

This work is part of doctoral dissertation, supported by a doctoral grant from the Open University of Catalonia (UOC), Spain.

\section{Notes on contributors}

Xanthippi Tsortanidou is a PhD candidate at Open University of Catalonia. She holds a Master in Curriculum Development from the University of Thessaly in Greece. Her research interests include Learning Design and Pedagogies, ICT and Collaborative Learning. 
Thanasis Daradoumis holds a PhD in Computer Science from the Polytechnic University of Catalonia. He combines his role as Associate Professor at the University of the Aegean, Department of Cultural Technology and Communication with his collaboration at the Open University of Catalonia within the Department of Computer Science, Multimedia and Telecommunications. He is also researcher at the Internet Interdisciplinary Institute (IN3) as well as at the eLearn Center (eLC). His research interests are: Emotional Intelligence, Alternative (Holistic) Education, Learning Analytics, E-learning, Collaborative, Affective and Adaptive Systems, CSCL. He has been advisor of over $20 \mathrm{MSc}$ theses and $8 \mathrm{PhD}$ already completed. He has published over 110 Scopus-indexed papers, from which over 20 are articles in ISI-JCR journals. He is a member of the editorial board of several international conferences and journals, whereas he has coordinated or participated in various National and European R\&D projects.

Elena Barberá-Gregori holds a PhD in Psychology (1995) and doctorate extraordinary award for the University of BarceIona (Spain). She is currently director of the Education and Technology PhD program and she is full professor at the Department of Psychology and Education Sciences at the Open University of Catalonia. Her research activity is focused on learning regulation and assessment, learning strategies and processes of teaching and learning in virtual contexts.

\section{ORCID}

Xanthippi Tsortanidou (iD http://orcid.org/0000-0002-3749-5794

Thanasis Daradoumis (iD http://orcid.org/0000-0001-9362-4469

Elena Barberá-Gregori (D) http://orcid.org/0000-0002-9315-8231

\section{References}

Aierbe-Barandiaran, A., \& Oregui-González, E. (2016). Valores y emociones en narraciones audiovisuales de ficción infantil. Comunicar, 24(47), 69-77.

Akti, S., \& Gürol, A. (2012). Determining the relationship between media literacy and social skills. Procedia - Social and Behavioral Sciences, 64, 238-243. doi:10.1016/j.sbspro.2012.11.028

Anderson, D. R., \& Kirkorian, H. L. (2015). Media and cognitive development. In R. M. Lerner (Ed.), Handbook of child psychology and developmental science (pp. 949-994). Wiley.

Anderson, D. R., \& Subrahmanyam, K. (2017). Digital screen media and cognitive development. Pediatrics, 140(Suppl. 2), S57-S61. doi:10.1542/peds.2016-1758C

Arslan, A. A. (2014). A study into the effects of art education on children at the socialisation process. Procedia-Social and Behavioral Sciences, 116, 4114-4118. doi:10.1016/j.sbspro.2014.01.900

Banks, T., Sapp, M., \& Obiakor, F. E. (2013). Understanding BF skinner: Building emotional competence in students with diverse learning needs. Multicultural Learning and Teaching, 9(1), 53-66. doi:10.1515/mlt-2013-0021

Blatt-Gross, C. (2010). Casting the conceptual net: Cognitive possibilities for embracing the social and emotional richness of art education. Studies in Art Education, 51(4), 353-367. Retrieved from http://www.naea-reston.org/research

Bourgeois, A., Bower, J., \& Carroll, A. (2014). Social networking and the social and emotional wellbeing of adolescents in Australia. Australian Journal of Guidance and Counselling, 24(2), 167-182. doi:10.1017/jgc.2014.14

Burnett, S., Thompson, S., Bird, G., \& Blakemore, S. J. (2011). Pubertal development of the understanding of social emotions: Implications for education. Learning and Individual Differences, 21(6), 681-689. doi:10.1016/j.lindif.2010. 05.007

Calvert, S. L. (2015). Children and digital media. In M. H. Bornstein, T. Leventahl, \& R. M. Lerner (Eds.), Handbook of child psychology and developmental science: Ecological settings and processes (pp. 375-415). Wiley.

Clark, S. J. (2007). The relationship between fine arts participation and the emotional intelligence of fifthgrade elementary students (Doctoral dissertation). Retrieved from https://scholarsarchive.byu.edu/etd/511/

Collier-Harris, C. A., \& Goldman, J. D. (2017). What educational contexts should teachers consider for their puberty education programmes? Educational Review, 69(1), 118-133.

Cooper, H. M. (1982). Scientific guidelines for conducting integrative research reviews. Review of Educational Research, 52 (2), 291-302. doi:10.3102\%2F00346543052002291

Cuff, B. M., Brown, S. J., Taylor, L., \& Howat, D. J. (2016). Empathy: A review of the concept. Emotion Review, 8(2), $144-153$. doi:10.1177\%2F1754073914558466

D'Amico, A. (2018). The use of technology in the promotion of children's emotional intelligence: The multimedia program "developing emotional intelligence". International Journal of Emotional Education, 10(1), 47-67.

Decety, J., \& Jackson, P. L. (2006). A social-neuroscience perspective on empathy. Current Directions in Psychological Science, 15(2), 54-58. doi:10.1111\%2Fj.0963-7214.2006.00406.x

Dill-Shackleford, K. E., Vinney, C., \& Hopper-Losenicky, K. (2016). Connecting the dots between fantasy and reality: The social psychology of our engagement with fictional narrative and its functional value. Social and Personality Psychology Compass, 10(11), 634-646. doi:10.1111/spc3.12274 
Eckhoff, A., \& Urbach, J. (2008). Understanding imaginative thinking during childhood: Sociocultural conceptions of creativity and imaginative thought. Early Childhood Education Journal, 36(2), 179-185. doi:10.1007/s10643-008-0261-4

Egan, K., \& Judson, G. (2009). Values and imagination in teaching: With a special focus on social studies. Educational Philosophy and Theory, 41(2), 126-140. doi:10.1111/j.1469-5812.2008.00455.x

Fleming, L. (2013). Expanding learning opportunities with transmedia practices: "inanimate alice" as an exemplar. Journal of Media Literacy Education, 5(2), 370-377. Retrieved from https://digitalcommons.uri.edu/jmle/vol5/iss2/3

Fletcher, N. M. (2016). Envisioning the experience of others: Moral imagination, practical wisdom, and the scope of empathy. Philosophical Inquiry in Education, 23(2), 141-159.

Franks, A. (2014). Drama and the representation of affect-structures of feeling and signs of learning. Research in Drama Education: The Journal of Applied Theatre and Performance, 19(2), 195-207. doi:10.1080/13569783.2014.895614

Friesem, Y. (2016). Empathy for the digital age: Using video production to enhance social, emotional, and cognitive skills. In S. Y. Tettegah \& D. L. Espelage (Eds.), Emotions, technology, and behaviors (pp. 21-45). Academic Press. doi:10.1016/ B978-0-12-801873-6.00002-9

Gallagher, S. (2012). Empathy, simulation, and narrative. Science in Context, 25(3), 355-381. doi:10.1017/S0269889712000117

Goldstein, T. R., \& Bloom, P. (2010). The effects of acting training on theory of mind, empathy, and emotion regulation (Unpublished doctoral dissertation). Retrieved from https://dlib.bc.edu/islandora/object/bc-ir:101519.

Graber, D., \& Mendoza, K. (2012). New media literacy education (NMLE): A developmental approach. Journal of Media Literacy Education, 4(1), 8.

Hatzigianni, M., Gregoriadis, A., \& Fleer, M. (2016). Computer use at schools and associations with social-emotional outcomes-a holistic approach. Findings from the longitudinal study of Australian children. Computers \& Education, 95, 134-150. doi:10.1016/j.compedu.2016.01.003

Hedegaard, M. (2016). Imagination and emotion in children's play: A cultural-historical approach. International Research in Early Childhood Education, 7(2), 59-74.

Higgins, E. T. (2016). Shared-reality development in childhood. Perspectives on Psychological Science, 11(4), $466-495$.

Hübner, E. (2015). Indirect and direct media pedagogy. In Struwwelpeter 2.0: Medienmündigkeit und Waldorfpädagogik.. In Media competency and Waldorf education (pp. 10-13). Bund der Freien Waldorfschulen.

laosanurak, C., Chanchalor, S., \& Murphy, E. (2016). Social and emotional learning around technology in a cross-cultural, elementary classroom. Education and Information Technologies, 21(6), 1639-1662. doi:10.1007/s10639-015-9406-4

Ioannidou, F., \& Konstantikaki, V. (2008). Empathy and emotional intelligence: What is it really about? International Journal of Caring Sciences, 1(3), 118.

Jones, A. (2010). Affective issues in learning technologies: Emotional responses to technology and technology's role in supporting socio-emotional skills. Journal of Interactive Media in Education, 2, 1-22.

Joronen, K., Häkämies, A., \& Åstedt-Kurki, P. (2011). Children's experiences of a drama programme in social and emotional learning. Scandinavian Journal of Caring Sciences, 25(4), 671-678. doi:10.1111/j.1471-6712.2011.00877.x

Keskin, S. C. (2014). From what isn't empathy to empathic learning process. Procedia-Social and Behavioral Sciences, 116, 4932-4938.

Kim, J. H., \& Wiehe-Beck, A. (2016). Understanding "the other" through art: Fostering narrative imagination in elementary students. International Journal of Education \& the Arts, 17(2), 1-34.

Kosic, M. (2018). Media literacy and social emotional learning for the net generation. International Journal of Emotional Education, 10(1), 68-88.

Kristjánsson, K. (2006). Emotional intelligence in the classroom? An Aristotelian critique. Educational Theory, 56(1), 39-56.

Maxwell, B., \& Reichenbach, R. (2005). Imitation, imagination and re-appraisal: Educating the moral emotions. Journal of Moral Education, 34(3), 291-307. doi:10.1080/03057240500206139

McCoy, C. (2012). Awakening students' sociological imagination. Contemporary Issues in Education Research, 5(2), 61-66.

Meline, T. (2006). Selecting studies for systemic review: Inclusion and exclusion criteria. Contemporary Issues in Communication Science and Disorders, 33(Spring), 21-27.

Mills, K. A., \& Unsworth, L. (2018). Ip ad animations: Powerful multimodal practices for adolescent literacy and emotional language. Journal of Adolescent \& Adult Literacy, 61(6), 609-620. doi:10.1002/jaal.717

Mynaříková, L. (2012). Art-based program for social and emotional development of children. US-China Education Review, 8, 720-726.

Neophytou, L. (2013). Emotional intelligence and educational reform. Educational Review, 65(2), 140-154.

Nielsen, M. I. (2017). Computer-mediated communication and self-awareness - a selective review. Computers in Human Behavior, 76, 554-560. doi:10.1016/j.chb.2017.08.015

Nielsen, T. W. (2006). Towards a pedagogy of imagination: A phenomenological case study of holistic education. Ethnography and Education, 1(2), 247-264. doi:10.1080/17457820600715455

Papoutsi, C., \& Drigas, A. (2017). Empathy and mobile applications. International Journal of Interactive Mobile Technologies (iJIM), 11(3), 57-66. doi:10.3991/ijim.v11i3.6385

Pfaff-Rüdiger, S., Riesmeyer, C., \& Kümpel, A. (2017). Media literacy and developmental tasks: A case study in Germany. Medijske Studije, 3(6), 42-57.

Pietschmann, D., Völkel, S., \& Ohler, P. (2014). Limitations of transmedia storytelling for children: A cognitive developmental analysis. International Journal of Communication, 8, 2259-2282. 
Robin, B. (2006, March). The educational uses of digital storytelling. Society for information technology \& teacher education international conference (pp. 709-716). Association for the Advancement of Computing in Education (AACE).

Rodriguez-Illera, J. L., \& Castells, N. M. (2014). Educational uses of transmedia storytelling. Journal of Educational Multimedia and Hypermedia, 23(4), 335-357.

Rosiek, J., \& Beghetto, R. A. (2009). Emotional scaffolding: The emotional and imaginative dimensions of teaching and learning. In P. Schutz \& M. Zembylas (Eds.), Advances in teacher emotion research. Boston, MA: Springer. doi:10. 1007/978-1-4419-0564-2 9

Ruokonen, l., \& Ruismäki, H. (2015). Artists at school-developing pupils' social interaction through artist-teacher co-operation. Procedia-Social and Behavioral Sciences, 171, 590-595. doi:10.1016/j.sbspro.2015.01.165

Sabatier, C., Restrepo Cervantes, D., Moreno Torres, M., Hoyos De los Rios, O., \& Palacio Sañudo, J. (2017). Emotion regulation in children and adolescents: Concepts, processes and influences. Psicología Desde el Caribe, 34(1), 101-110.

Santos, C. M. D. C., Pimenta, C. A. D. M., \& Nobre, M. R. C. (2007). The PICO strategy for the research question construction and evidence search. Revista Latino-Americana de Enfermagem, 15(3), 508-511.

Savina, E., Mills, J. L., Atwood, K., \& Cha, J. (2017). Digital media and youth: A primer for school psychologists. Contemporary School Psychology, 21(1), 80-91.

Shank, M. (2016). Imagination, Waldorf, and critical literacies: Possibilities for transformative education in mainstream schools. Reading \& Writing-Journal of the Reading Association of South Africa, 7(2), 1-9.

Silva, B., Cruz, E., \& Laureano-Cruces, A. (2006, October). An analysis for identifying the learning styles for modeling the knowledge domain. ANIEI XIX national conference and V international conference of informatics and computing, Tuxtla Gutiérrez, Chiapas.

Stehlik, T. (2008). Thinking, feeling, and willing: How Waldorf schools provide a creative pedagogy that nurtures and develops imagination. In T. Leonard \& P. Willis (Eds.), Pedagogies of the imagination (pp. 231-243). Dordrecht: Springer.

Trimmel, M., \& Bachmann, J. (2004). Cognitive, social, motivational and health aspects of students in laptop classrooms. Journal of Computer Assisted Learning, 20, 151-158.

Warin, J., \& Muldoon, J. (2009). Wanting to be 'known': Redefining self-awareness through an understanding of self-narration processes in educational transitions. British Educational Research Journal, 35(2), 289-303.

Whalen, L. (2010). The neuroscience of teaching narratives: Facilitating social and emotional development. BRAIN, Broad Research in Artificial Intelligence and Neuroscience, 1(2), 143-148.

Wilce, J. M., \& Fenigsen, J. (2016). Emotion pedagogies: What are they, and why do they matter? Ethos, 44(2), 81-95.

Wilson, B. J. (2008). Media and children's aggression, fear, and altruism. The Future of Children, 18(1), 87-118.

Wirling, Y. (2014). Imagining oneself being someone else. Journal of Consciousness Studies, 21(9-10), 205-225.

Ying, L., \& Blanchfield, P. (2010, October). Learning communication skills by making cartoon films. European conference on games based learning. Academic Conferences International Limited. Orlando, FL, March 2006. Association for the Advancement of Computing in Education (AACE).

You, S., Lee, J., Lee, Y., \& Kim, E. K. (2018). The effects of middle school art class with an empathy-based learning model. Current Psychology, 1-11. 